\title{
Clinical and Magnetic Resonance Imaging Findings of Neurotoxocariasis
}

\author{
Sofia S. Sánchez ${ }^{1,2}$, Hector H. Garcia ${ }^{1,2,3 *}$ and Alessandra Nicoletti ${ }^{4}$ \\ 'Department of Microbiology, School of Public Health (SSS), Center for Global Health - Tumbes (HHG), Universidad Peruana \\ Cayetano Heredia, Lima, Peru, ${ }^{2}$ School of Sciences (HHG), Center for Global Health - Tumbes (HHG), Universidad Peruana \\ Cayetano Heredia, Lima, Peru, ${ }^{3}$ Cysticercosis Unit, Instituto Nacional de Ciencias Neurologicas, Lima, Peru, ${ }^{4}$ Department G. \\ F. Ingrassia, Section of Neurosciences, University of Catania, Catania, Italy
}

OPEN ACCESS

Edited by:

U. K. Misra,

Sanjay Gandhi Post Graduate Institute of Medical Sciences, India

Reviewed by:

Zafar Neyaz,

Sanjay Gandhi Post Graduate Institute of Medical Sciences, India Kenichi Oishi,

Johns Hopkins University, United States

*Correspondence: Hector H. García hgarcia@jhsph.edu

Specialty section: This article was submitted to Neuroinfectious Diseases, a section of the journal Frontiers in Neurology

Received: 03 November 2017 Accepted: 19 January 2018 Published: 08 February 2018

Citation:

Sánchez SS, García HH and Nicoletti A (2018) Clinical and Magnetic Resonance Imaging Findings of Neurotoxocariasis.

Front. Neurol. 9:53. doi: 10.3389/fneur.2018.00053
Human toxocariasis is one of the most prevalent helminthiases worldwide. Toxocara canis larvae can cross the blood-brain barrier leading to the neurotoxocariasis. The clinical presentation consists of a wide spectrum of neurological manifestations, but asymptomatic infection is probably common. Neurotoxocariasis is not a frequent diagnosis probably due to the non-specific nature of its symptoms as well as the lack of confirmatory diagnostic tests. Diagnosis of neurotoxocariasis is based on the presence of a high titer of anti-Toxocara antibody in the cerebrospinal fluid or in the serum, presence of eosinophilia in the serum or cerebrospinal fluid, and clinical and radiological improvement after anthelmintic therapy; however, universally accepted diagnostic criteria are lacking. Magnetic resonance imaging (MRI) findings include single or multiple, subcortical, cortical or white matter hyperintense lesions, best visualized on FLAIR and T2-weighted imaging, and usually isointense or hypointense on T1. These imaging findings are suggestive but not specific to neurotoxocariasis. Definitive diagnosis is made by histological confirmation, but it is rarely followed. This review provides an overview of the clinical manifestations, management options, and MRI findings of neurotoxocariasis.

Keywords: toxocariasis, central nervous system infections, neurotoxocariasis, helminths, myelitis

\section{INTRODUCTION}

\section{Life Cycle and Epidemiology}

Human toxocariasis is a parasitic zoonosis caused by the larval stages of the ascarids Toxocara canis, the common roundworm of dogs, and probably by the roundworm of cats (Toxocara cati) as well. Among the helminthiases, toxocariasis is one of the most prevalent worldwide, especially in settings where human-soil-dog contact is particularly common. Even if the parasite tends to be more prevalent in tropical settings, seroprevalence reaches up to $80-90 \%$ in Western countries ranging from 35 to $42 \%$ in rural areas and from 2 to $5 \%$ in urban areas (1).

Toxocara is a nematode that usually inhabits the small intestine of the host; dogs can become infected by transplacental spread or by contact with contaminated feces. The female Toxocara produces up to 200,000 eggs per day, releasing them to the environment through the dog's feces (2). Humans can become infected by direct contact with dogs or by the ingestion of contaminated food or soil. Ingested eggs develop into juvenile larvae that cross the small intestine and migrate to any organ through the circulatory system, resulting in a multisystemic inflammatory tissue reaction. Visceral larva migrans (VLM) and ocular larva migrans are the most common clinical manifestations (3). More recently, two different syndromes have been described: covert toxocariasis, which is more common in children and common toxocariasis, reported in adults, both characterized by mild Toxocara infection and less-severe systemic manifestations (4). 


\section{Central Nervous System (CNS) Infection}

Toxocaracanislarvaecan cross theblood-brainbarrier, invading the CNS, leading to neurotoxocariasis. Autopsy studies have revealed T. canis larvae in the leptomeninges, both the gray and white matter of the cerebrum, the cerebellum, and the spinal cord (5-10). However, most of these cases did not have clinical neurological signs and, for this reason, the clinical significance and true frequency of cerebral localization of Toxocara larvae remain unknown. To date, CNS infestation of T. canis larvae in humans is thought to be rare, even if in animal models larvae often migrate to the brain (11).

Asymptomatic CNS infection is probably common, clinically apparent neurotoxocariasis consists of a wide spectrum of neurological manifestations from meningitis, encephalitis, and myelitis, to cerebral vasculitis (1). Peripheral nervous system manifestations of toxocariasis have been reported in a few cases and comprise radiculitis, affection of cranial nerves, or musculoskeletal involvement (12). According to two recent reviews, approximately 100 cases of neurotoxocariasis have been reported in the literature since 1956. A possible association between $T$. canis and epilepsy has been suggested by several case-control studies $(13,14)$.

\section{Diagnosis of Neurotoxocariasis}

Neurotoxocariasis is not a frequent diagnosis and it is probably underdiagnosed due to the non-specific nature of its symptoms (seizures and headache) exacerbated by a lack of confirmatory diagnostic tests. Diagnosis of neurotoxocariasis is based on the presence of a high titer of anti-Toxocara antibody in the CSF or in the serum, presence of eosinophilia in the serum or CSF, and clinical and radiological improvement after anthelmintic therapy $(12,15)$, but validated diagnostic criteria are lacking. The standard serological test is an ELISA based on secretory-excretory antigens (TES) from Toxocara canis larvae of the second stage (16). These antigens are a mixture of several glycoproteins that have Th2 type immune response with high levels of interleukin (IL) 4 and IL5. ELISA for the detection of specific IgG antibodies to TES in serum has a sensitivity of $78 \%$ and a specificity of $92 \%$ for the diagnosis of VLM, although cross-reactions with other nematode infections reduce its specificity, particularly in tropical areas $(17,18)$. As for any antibody test, a positive IgG ELISA cannot distinguish between past and current infection, although decreasing antibody titers after antihelminthic treatment or following clinical remission are highly suggestive of the diagnosis (18).

The use of fractionated native TES in the western blot (WB) assay overcomes the issues with cross-reactions to other nematodes in ELISA assays because the low molecular weight bands (24-32 kDa) are specific for Toxocara infection (19). Unfortunately, western blotting is more expensive and labor-intensive than ELISA, and thus screening with the indirect TES-IgG-ELISA, followed by confirmation with the TES-WB, is considered an effective approach $(18,20)$.

A variety of brain imaging findings have been reported in relation to neurotoxocariasis, initially using computed tomography and more recently, using magnetic resonance imaging (MRI). Despite the evident importance of characterization of neuroimaging findings, few studies have evaluated neurotoxocariasis by MRI. We carried out a systematic review to investigate the clinical manifestations, management options, and MRI characteristics of cerebral toxocariasis.

\section{METHODS}

We used the following search strategy ((“"toxocariasis") OR ("toxocariosis") AND "central nervous system") OR "neurotoxocariasis") OR ("Toxocara canis" AND "central nervous system") to identify neurotoxocariasis cases recorded in PubMed until March 1, 2017. We evaluated articles in English, Spanish, Portuguese, and French that reported original data of case reports or case series. We included only cases that underwent an MRI study. Cases describing peripheral nervous system involvement were not included because the main aim of this review was to evaluate the MRI characteristics of neurotoxocariasis in the CNS. Epidemiological studies such as case-control studies assessing the association between neurotoxocariasis and epilepsy were also excluded. A search of the reference lists of the identified articles led to identification of further relevant articles.

\section{CLINICAL AND MRI FINDINGS}

Since the first reported case of neurotoxocariasis who underwent a brain MRI, published in 1991, we identified 48 articles (21-68) including three case series $(25,27,28)$ involving a total of 104 patients with neurological manifestations in the CNS [either myelitis $(n=70,67.3 \%)$ or cerebral toxocariasis $(n=34,32.7 \%)]$. Most patients were men $(79,76.0 \%)$ and their mean age was $42.3 \pm 15.2$ years (SD). Histological confirmation was obtained in only seven cases. Detailed information on the 104 reported cases is provided in Table S1 in Supplementary Material.

\section{Myelitis}

Isolated myelitis represents the most commonly reported presentation, occurring in 70 cases [61 men (87.1\%); mean age $45.1 \pm 9.8$ years] $(21-36)$; three of them were classified as meningomyelitis due to the presence of local leptomeningeal involvement $(30,31,34)$.

The majority of cases were reported in three different case series including 17,8 , and 31 cases $(25,27,28)$. Clinical manifestations included sensory and motor disturbances, predominantly involving the lower limbs and often accompanied by autonomic dysfunction. Liver or lung involvement was reported in nine patients $(12.9 \%)(26,28)$.

On MRI, spinal toxocariasis is characterized by swelling and enlargement of the involved spinal segment and hyperintensity on T2 and FLAIR sequences with focal nodular enhancement after gadolinium injection (Figure 1). The enhancing area is generally smaller than the affected area with a tendency to involve the posterior-lateral areas of the cord (Figure 2). Lesions varied in size; they were almost always singular and located at the thoracic and cervical levels (Table S1 in Supplementary Material).

ELISA for anti-Toxocara antibodies in the CSF was assessed in 38 patients and was positive in all (100\%); a confirmatory WB in CSF was available for 20 patients. For 31 patients (44.3\%), the 


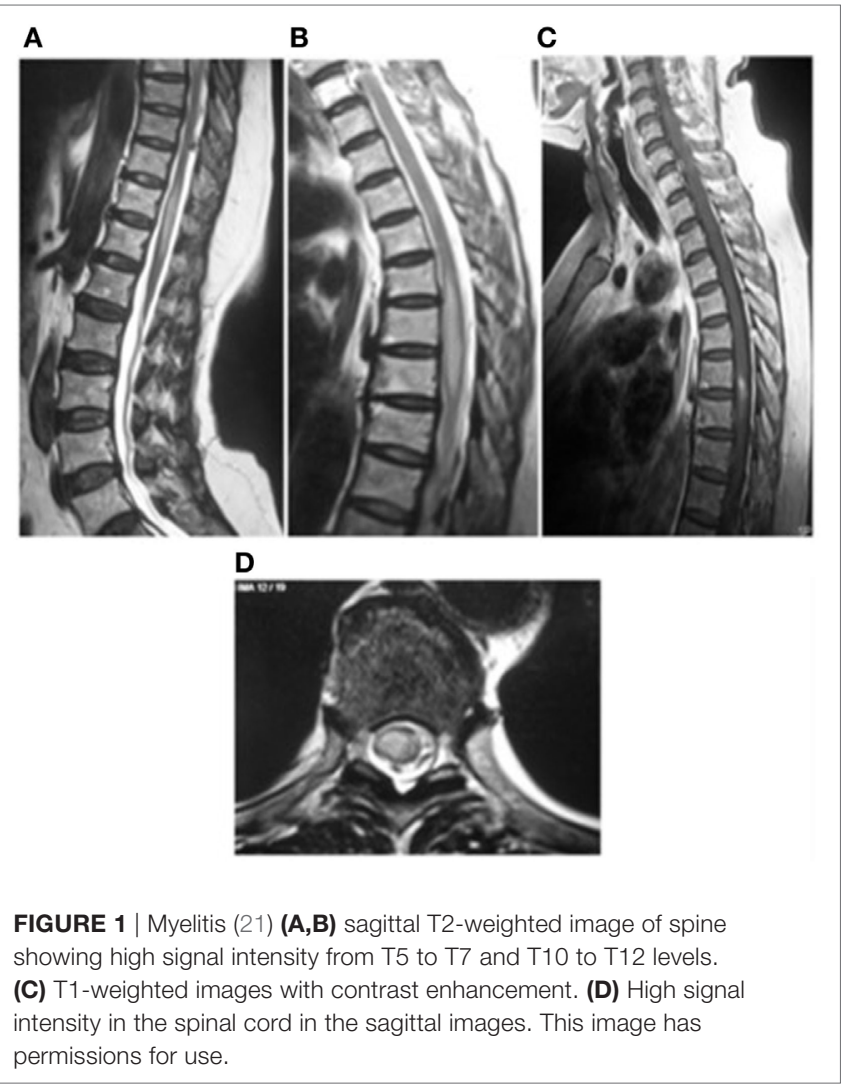

diagnosis was based on ELISA seropositivity, confirmed by WB only in 9 patients (24 presented also elevated serum $\operatorname{IgE}$ ); in 1 patient with serum antibodies detected by ELISA, the diagnosis was confirmed by biopsy (23).

Mild-moderate blood eosinophilia was reported in 36 cases (51.4\%) while CSF analysis was performed in 62 cases of whom only 21 (33.9\%) presented with CSF eosinophilic pleocytosis (Table S1 in Supplementary Material; Table 1). When reported (39 cases) IgE level was always high $(>150 \mathrm{U} / \mathrm{ml})$. Diagnosis was confirmed by biopsy in only one of the patients with eosinophilia (23).

Fifty-four patients $(77.1 \%)$ received anthelmintic treatment (albendazole in 50 cases), almost always with concomitant corticosteroid therapy $(n=52)$, while corticosteroids alone were administered only in 16 cases. After treatment, almost all patients improved clinically (only one remained stable) and radiologically, including those treated only with corticosteroids.

Changes in antibody titers after treatment were only evaluated in a few cases and at different follow-up times with conflicting results $(24,28,31,33,34)$.

\section{Cerebral Toxocariasis}

Encephalic localization has been reported in 34 patients [18 men (54.5\%); mean age $33.5 \pm 21.3$ years]; 2 patients were classified as meningitis $(38,52), 1$ as encephalitis (37), 4 as meningoencephalitis $(46,53,54,58), 3$ as encephalomyelitis $(29,49,51), 1$ as meningoencephalomyelitis(55), 2 as cerebral abscess $(41,50)$, and 1 as obstructive hydrocephalus (61). Thirteen

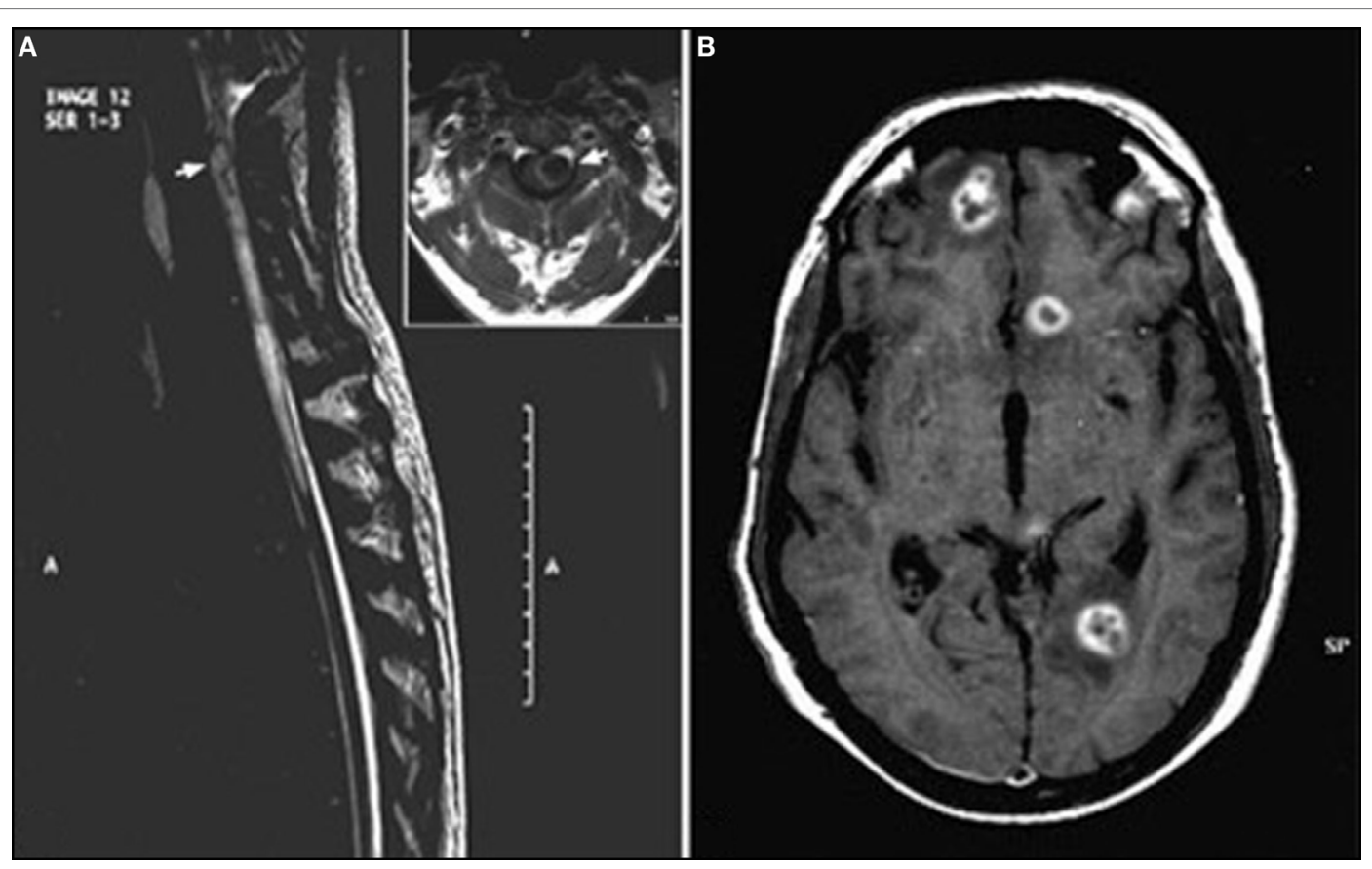

FIGURE 2 | Encephalomyelitis (50) (A) T2-weighted sagittal image of spine showing a hyperintense lesion (arrow) with extensive perilesional edema in the upper cervical cord. Inset highlights large lesion (arrow) with peripheral hyperintense rim and perilesional edema causing expansion of cervical cord. (B) T1-weighted axial post-contrast image of brain shows multiple ring-enhancing lesions in bilateral frontoparietal deep white matter with nodular enhancement of the wall seen in left frontal lesion. This image has permissions for use. 
TABLE 1 | Blood and CSF characteristics.

\begin{tabular}{lcc}
\hline & $\begin{array}{c}\text { Myelitis } \\
(\boldsymbol{n}=\mathbf{7 0})\end{array}$ & $\begin{array}{c}\text { Cerebral toxocariasis } \\
(\boldsymbol{n}=\mathbf{3 4 )}\end{array}$ \\
\hline Peripheral eosinophilia & $36 / 70(51.4 \%)$ & $28 / 33(84.9 \%)$ \\
CSF pleocytosis & $21 / 62(33.9 \%)$ & $19 / 29(65.5 \%)$ \\
Positive serum ELISA & $69^{\mathrm{a} / 70}(98.6 \%)$ & $32 / 32^{\mathrm{d}}(100 \%)$ \\
Positive serum western blot (WB) & $29 / 32(90.6 \%)$ & $8 / 8(100 \%)$ \\
Positive CSF ELISA & $38 / 38(100 \%)$ & $18^{\mathrm{b}} / 23(78.3 \%)$ \\
Positive CSF WB & $20 / 20(100 \%)$ & $8^{\mathrm{c}} / 8(100 \%)$ \\
Biopsy & $1 / 70(1.4 \%)$ & $6 / 34(17.6 \%)$ \\
\hline
\end{tabular}

${ }^{a}$ Two cases = enzyme immunoassay (EIA).

${ }^{\circ}$ One case $=E I A$

${ }^{\circ}$ One case $=$ CSF PCR

${ }^{d}$ One case $=$ immunofluorescence.

were generically defined as cerebral toxocariasis $(21,39,40$, $42-45,47,48,56,57,59,60)$ and seven were classified as vasculitis (62-68).

Encephalic/meningeal toxocariasis involvement was associated with a wide range of clinical manifestations including headache, seizures, focal deficits, confusional state, and cognitive impairment, with or without fever. A case of obstructive hydrocephalus due to toxocariasis was reported in a 46-year-old man who developed headache, diplopia, and visual deficits (61). Concomitant liver or lung involvement was reported only in two patients. CNS vasculitis was a rare and severe presentation that manifested as headache, cognitive impairment, and acute ischemic events and was described in seven patients; in three of them, liver or lung involvement was also reported (62-64).

Magnetic resonance imaging findings are not specific, showing single or multiple subcortical, cortical, or white matter hyperintense lesions on FLAIR and T2WI, usually isointense or hypointense in T1WI (Figure 1). Homogeneous or punctate enhancement after gadolinium injection was observed in nine cases, and single or multiple ring-enhancing lesions were described in four cases (Figure 2) $(41,42,44,50)$. Focal meningeal contrast enhancement, next to an active inflammatory lesion, was described in three patients $(55,59,61)$. In the patient with obstructive hydrocephalus (61), brain MRI revealed hydrocephalus and leptomeningeal enhancement at the prepontine cistern, left cerebellopontine angle cistern, bilateral cerebral hemisphere, and a non-enhancing mass posterior to cerebral aqueduct. Imaging of the patients with vasculitis generally showed ischemic lesions; in four of the seven cases, diffusion-weighted imaging sequences were also performed demonstrating the presence of multifocal acute infarctions $(62,63,66,67)$. MRI angiography was performed only in one case (65) showing numerous segmental and irregular stenoses of the encephalic arteries; angiography (68) was also performed in one patient showing the occlusion of multiple small branches of the middle cerebral artery.

Anti-Toxocara antibodies in CSF were assessed in 24 cases (nineteen by ELISA, six by ELISA and WB, and two by WB). Out of the 19 patients assessed by CSF ELISA, 15 tested positive of whom three were also confirmed by positive WB; in two additional patients, the presence of anti-Toxocara antibodies was detected only by WB. In 10 patients, of whom 4 were vasculitis $(62,63$,
$67,68)$, in which the diagnosis of neurotoxocariosis was based only on the presence of a positive serum ELISA seropositivity [CSF ELISA was negative in $5(39,47,48,59,63)$ and not performed in the other $5(53,56,62,67,68)]$, not confirmed by biopsy or WB (Table 1; Table S1 in Supplementary Material).

A mild-moderate eosinophilia was reported in 28 cases (84.9\%); CSF analysis was performed in 24 patients of whom 17 had CSF pleocytosis (14 with eosinophilic pleocytosis). IgE levels were reported only in five patients and were elevated in four (Table S1 in Supplementary Material).

The diagnosis of encephalic/meningeal neurotoxocariasis was confirmed by biopsy in six cases $(41,42,44,50,58,60)$. Histopathological examination generally showed a granulomatous inflammatory response containing large numbers of eosinophils and neutrophils in the parenchyma with perivascular lymphocytic infiltrate. Toxocara larvae were detected in only two cases. The absence of larvae can be explained by the fact that the larvae are not permanently trapped by the reaction of the host but rather can escape, migrate, and trigger other inflammatory foci $(59,69)$. Out of these six confirmed cases, two presented with anti-Toxocara antibodies in the CSF. CSF analysis was not performed in four cases.

Twenty-three patients were treated with anthelmintic medications; seventeen received albendazole while the others received thiabendazole, mebendazole, or diethylcarbamazine. Fifteen of these patients were treated with concomitant corticosteroids. Clinical improvement with complete recovery was observed in all except two patients who suffered a relapse. The only death occurred in a 46-year-old woman with meningoencephalitis (53). However, it should be noted that in this case, eosinophilia and pleocytosis were absent and the diagnosis was based only on a positive serum IgG ELISA, not confirmed by biopsy (53). Two cases spontaneously improved without treatment $(47,52)$. Posttreatment brain MRI generally showed improvement, whereas antibodies were monitored in a few patients with variable results.

\section{DISCUSSION}

Toxocariasis is highly prevalent; however, neurotoxocariasis is rarely taken into account as a differential diagnosis in clinical settings. The diagnosis of neurotoxocariasis is a challenge because there is no distinct clinical syndrome. Imaging studies reported to date are not specific and serology has low specificity and sensitivity. In many reports, the diagnosis was only presumptive. Definitive diagnosis is given by histological confirmation, which is rarely available. Our systematic review demonstrated an impressive variation in case definitions and diagnostic evaluations. MRI findings in this large population were all suggestive, but none of them can be considered specific to neurotoxocariosis, and most of these findings can be seen in many other infectious or inflammatory conditions.

About $40 \%$ patients were diagnosed on the basis of serum IgG antibody detection by ELISA only. A positive IgG ELISA in serum to confirm the diagnosis may be of minimal value because of seroprevalence of $90 \%$, particularly in tropical areas, and the ELISA frequently cross-reacts with other nematode infections $(18,20)$. Several studies have found that the antibody load decreases as time passes and after treatment (70). Thus, a more 
reliable marker of disease could be given by the normalization of antibody titers after treatment. Unfortunately, this finding was reported in only few cases with a wide variety of follow-up times, leading to inconsistent results.

On the other hand, peripheral eosinophilia was present in $64 \%$ and CSF pleocytosis in $40 \%$. Their absence thus does not exclude CNS Toxocara involvement, an important finding because clinicians tend to look for eosinophilia as a basis to suspect a parasitic infection. Increased serum IgE levels were almost always positive, but reported in only $41 \%$ of the cases.

A diagnosis of neurotoxocariasis is also supported by clinical and MRI improvement after specific anthelmintic treatment. In $90 \%$ or more of cases, the drug used was albendazole. However, there are no specific guidelines for the treatment of neurotoxocariasis. Patients were treated with anthelmintics and corticosteroids in different dosage and administration schedules. In some cases, the improvement may have resulted from corticosteroid treatment that represents the first-line drug for several autoimmune inflammatory conditions characterized by similar MRI findings and thus would not necessarily support the diagnosis of neurotoxocariasis. Moreover, spontaneous remission has also been reported.

It follows that for a significant proportion of reported neurotoxocariasis cases, other infectious, particularly, parasitic or inflammatory etiologies cannot be definitively ruled out. In particular, in the case of myelitis, which comprised nearly $70 \%$ of the identified cases, other causes of autoimmune myelopathies should be suspected. Autoimmune myelopathies are a heterogeneous group of immune-mediated spinal cord disorders encompassing myelopathies with an immune attack on the spinal cord (e.g., aquaporin-4-IgG seropositive neuromyelitis optica), myelopathies occurring with systemic autoimmune disorders, paraneoplastic autoimmune myelopathies, postinfectious autoimmune myelopathies, and myelopathies considered to be immune related (e.g., multiple sclerosis and sarcoidosis) (71). These conditions are not distinguishable simply on the basis of MRI findings and can often improve after corticosteroid treatment. It should be emphasized that while a complete screening for other infectious conditions is almost always reported, screening for autoimmunity was performed only in few cases. For example, aquaporin-4 antibody was tested in just two cases.

Likewise, concerning cerebral toxocariasis, MRI often reveals the presence of a granulomatous process leading to reversible single or multiple ring-enhancing lesions. However, ring-enhancing

\section{REFERENCES}

1. Fan C-K, Holland CV, Loxton K, Barghouth U. Cerebral toxocariasis: silent progression to neurodegenerative disorders? Clin Microbiol Rev (2015) 28(3):663-86. doi:10.1128/CMR.00106-14

2. Glickman LT, Schantz PM. Epidemiology and pathogenesis of zoonotic toxocariasis. Epidemiol Rev (1981) 3:230-50. doi:10.1093/oxfordjournals. epirev.a036235

3. Schantz PM, Glickman LT. Toxocaral visceral larva migrans. $N$ Engl J Med (1978) 298(8):436-9. doi:10.1056/NEJM197802232980806

4. Taylor MR, Keane CT, O'Connor P, Girdwood RW, Smith H. Clinical features of covert toxocariasis. Scand J Infect Dis (1987) 19(6):693-6. doi: $10.3109 / 00365548709117206$ lesions are a common finding that can be related to different disease processes such as infective, neoplastic, and inflammatory conditions. In particular, single enhancing lesions (SEL) represent a frequent diagnostic dilemma in tropical countries where they are generally due to infectious diseases such as neurocysticercosis and tuberculosis. In T. solium endemic areas, the presence of an SEL and its resolution after cysticidal drug therapy are considered to be major definitive criteria for the diagnosis of neurocysticercosis (72). However, single cysticercus granulomas are frequently seronegative for antibodies to T. solium, and in this scenario, a diagnosis of neurotoxocariasis cannot be entirely ruled out.

In conclusion, due to the lack of widely accepted, standard diagnostic criteria, there is a great variability in case definitions, diagnostic procedures, and diagnostic certainty for neurotoxocariasis. As suggested by data from animal models, larvae often migrate to the brain and neurotoxocariasis is probably less rare than assumed; like many tropical infectious diseases, it is often neglected and rarely diagnosed. MRI findings include single or multiple subcortical, cortical, or white matter hyperintense lesions, best visualized on FLAIR and T2-weighted imaging, and usually isointense or hypointense on T1. These imaging findings are suggestive but not specific to neurotoxocariasis. The main clinical manifestations of neurotoxocariasis are myelitis (present in approximately two-thirds of all reported cases), encephalitis, and meningitis. Neurotoxocariasis should be included in the differential diagnosis of cases of meningeal, cerebral, or spinal cord disease of unknown origin.

\section{AUTHOR CONTRIBUTIONS}

All authors (SS, HG, and AN) participated in conception and organization of review, literature search, and all stages of writing from initial draft to final product.

\section{ACKNOWLEDGMENTS}

We are indebted to Dr. Farrah Mateen and Maggie Cochran for their thorough review and edition of this manuscript. SS is supported by FIC-NIH training grant D43TW001140.

\section{SUPPLEMENTARY MATERIAL}

The Supplementary Material for this article can be found online at http://www.frontiersin.org/articles/10.3389/fneur.2018.00053/ full\#supplementary-material.

5. Dent JH, Nichols RL, Beaver PC, Carrera GM, Staggers RJ. Visceral larva migrans; with a case report. Am J Pathol (1956) 32(4):777-803.

6. Moore MT. Human Toxocara canis encephalitis with lead encephalopathy. J NeuropatholExpNeurol(1962)21:201-18.doi:10.1097/00005072-19620400000004

7. Beautyman W, Beaver PC, Buckley JJ, Woolf AL. Review of a case previously reported as showing an ascarid larva in the brain. J Pathol Bacteriol (1966) 91(1):271-3. doi:10.1002/path.1700910136

8. Schochet SS. Human Toxocara canis encephalopathy in a case of visceral larva migrans. Neurology (1967) 17(3):227-9. doi:10.1212/WNL.17.3.227

9. Hill IR, Denham DA, Scholtz CL. Toxocara canis larvae in the brain of a British child. Trans R Soc Trop Med Hyg (1985) 79(3):351-4. doi:10.1016/0035-9203 (85)90378-5 
10. Mikhael NZ, Montpetit VJ, Orizaga M, Rowsell HC, Richard MT. Toxocara canis infestation with encephalitis. Can J Neurol Sci (1974) 1(2):114-20. doi:10.1017/S0317167100019661

11. Graeff-Teixeira C, da Silva ACA, Yoshimura K. Update on eosinophilic meningoencephalitis and its clinical relevance. Clin Microbiol Rev (2009) 22(2):322-48. doi:10.1128/CMR.00044-08

12. Finsterer J, Auer H. Neurotoxocariosis. Rev Inst Med Trop Sao Paulo (2007) 49(5):279-87. doi:10.1590/S0036-46652007000500002

13. Quattrocchi G, Nicoletti A, Marin B, Bruno E, Druet-Cabanac M, Preux P-M. Toxocariasis and epilepsy: systematic review and meta-analysis. PLoS Negl Trop Dis (2012) 6(8):e1775. doi:10.1371/journal.pntd.0001775

14. Deshayes S, Bonhomme J, de La Blanchardière A. Neurotoxocariasis: a systematic literature review. Infection (2016) 44(5):565-74. doi:10.1007/s15010-016-0889-8

15. Nicoletti A. Toxocariasis. Handb Clin Neurol (2013) 114:217-28. doi:10.1016/ B978-0-444-53490-3.00016-9

16. de Savigny DH, Voller A, Woodruff AW. Toxocariasis: serological diagnosis by enzyme immunoassay.J Clin Pathol (1979) 32(3):284-8. doi:10.1136/jcp.32.3.284

17. Fillaux J, Magnaval JF. Laboratory diagnosis of human toxocariasis. Vet Parasitol (2013) 193(4):327-36. doi:10.1016/j.vetpar.2012.12.028

18. Ma G, Holland CV, Wang T, Hofmann A, Fan CK, Maizels RM, et al. Human toxocariasis. Lancet Infect Dis (2018) 18(1):e14-24. doi:10.1016/ S1473-3099(17)30331-6

19. Magnaval JF, Fabre R, Maurières P, Charlet JP, de Larrard B. Application of the western blotting procedure for the immunodiagnosis of human toxocariasis. Parasitol Res (1991) 77(8):697-702. doi:10.1007/BF00928685

20. Rubinsky-Elefant G, Hirata CE, Yamamoto JH, Ferreira MU. Human toxocariasis: diagnosis, worldwide seroprevalences and clinical expression of the systemic and ocular forms. Ann Trop Med Parasitol (2010) 104(1):3-23. doi:10.1179/136485910X12607012373957

21. Abir B, Malek M, Ridha M. Toxocariasis of the central nervous system: with report of two cases. Clin Neurol Neurosurg (2017) 154:94-7. doi:10.1016/j. clineuro.2017.01.016

22. Hiramatsu Y, Yoshimura M, Saigo R, Arata H, Okamoto Y, Matsuura E, et al. Toxocara canis myelitis involving the lumbosacral region: a case report. J Spinal Cord Med (2015) 7:1-15.

23. Park CW, Choe WJ, Chun YI. Eosinophilic myelitis in the cervical cord mimicking intramedullary cord tumor. J Korean Neurosurg Soc (2012) 52(4):410-3. doi: $10.3340 / \mathrm{jkns} .2012 .52 .4 .410$

24. Fukae J, Kawanabe T, Akao N, Kado M, Tokoro M, Yokoyama K, et al. Longitudinal myelitis caused by visceral larva migrans associated with Toxocara cati infection: case report. Clin Neurol Neurosurg (2012) 114(7):1091-4. doi:10.1016/j.clineuro.2012.02.026

25. Jabbour RA, Kanj SS, Sawaya RA, Awar GN, Hourani MH, Atweh SF. Toxocara canis myelitis: clinical features, magnetic resonance imaging (MRI) findings, and treatment outcome in 17 patients. Medicine (Baltimore) (2011) 90(5):337-43. doi:10.1097/MD.0b013e31822f63fb

26. Ota KV, Dimaras H, Héon E, Gallie BL, Chan HSL. Radiologic surveillance for retinoblastoma metastases unexpectedly showed disseminated toxocariasis in liver, lung, and spinal cord. Can J Ophthalmol (2010) 45(2):185-6. doi:10.3129/i09-216

27. Lee IH, Kim ST, Oh DK, Kim H-J, Kim KH, Jeon P, et al. MRI findings of spinal visceral larva migrans of Toxocara canis. Eur J Radiol (2010) 75(2):236-40. doi:10.1016/j.ejrad.2009.04.024

28. Lee J-Y, Kim B-J, Lee S-P, Jeung Y-J, Oh M-J, Park M-S, et al. Toxocariasis might be an important cause of atopic myelitis in Korea. J Korean Med Sci (2009) 24(6):1024-30. doi:10.3346/jkms.2009.24.6.1024

29. Umehara F, Ookatsu H, Hayashi D, Uchida A, Douchi Y, Kawabata H, et al. MRI studies of spinal visceral larva migrans syndrome. J Neurol Sci (2006) 249(1):7-12. doi:10.1016/j.jns.2006.05.057

30. Dauriac-Le Masson V, Chochon F, Demeret S, Pierrot-Deseilligny C. Toxocara canis meningomyelitis. J Neurol (2005) 252(10):1267-8. doi:10.1007/s00415005-0688-0

31. Eberhardt O, Bialek R, Nägele T, Dichgans J. Eosinophilic meningomyelitis in toxocariasis: case report and review of the literature. Clin Neurol Neurosurg (2005) 107(5):432-8. doi:10.1016/j.clineuro.2004.10.003

32. Radman N, Guardis M, Schamun A, Testi A, Archelli S, Fonrouge R, et al. Toxocarosis neurológica: descripción de un caso clínico. Rev Chil NeuroPsiquiat (2000) 38:196-200. doi:10.4067/S0717-92272000000300007
33. Goffette S, Jeanjean AP, Duprez TP, Bigaignon G, Sindic CJ. Eosinophilic pleocytosis and myelitis related to Toxocara canis infection. Eur J Neurol (2000) 7(6):703-6. doi:10.1046/j.1468-1331.2000.00123.x

34. Strupp M, Pfister HW, Eichenlaub S, Arbusow V. Meningomyelitis in a case of toxocariasis with markedly isolated CSF eosinophilia and an MRIdocumented thoracic cord lesion. J Neurol (1999) 246(8):741-4. doi:10.1007/ s004150050446

35. DuprezTP,Bigaignon G, DelgrangeE, DesfontainesP,HermansM, VervoortT, et al. MRI of cervical cord lesions and their resolution in Toxocara canis myelopathy. Neuroradiology (1996) 38(8):792-5. doi:10.1007/ s002340050350

36. Kumar J, Kimm J. MR in Toxocara canis myelopathy. AJNR Am J Neuroradiol (1994) 15(10):1918-20.

37. Caldera F, Burlone ME, Genchi C, Pirisi M, Bartoli E. Toxocara encephalitis presenting with autonomous nervous system involvement. Infection (2013) 41(3):691-4. doi:10.1007/s15010-012-0342-6

38. Keller M, Pavia AT, Byington CL. Possible intrafamilial transmission of Toxocara causing eosinophilic meningitis in an infant. Pediatr Infect Dis $J$ (2008) 27(9):849-50. doi:10.1097/INF.0b013e3181719bd1

39. Kinceková J, Bánovčin B, Fedor M, Dubinský PJ, Polácek H, Pavlinova J, et al. A case of complicated cerebral toxocariasis in a 4-year old child. Helminthologia (2008) 45:169-72. doi:10.2478/s11687-008-0034-z

40. Scheid R, Tina Jentzsch R, Schroeter ML. Cognitive dysfunction, urinary retention, and a lesion in the thalamus - beware of possible toxocariasis of the central nervous system. Clin Neurol Neurosurg (2008) 110(10):1054-7. doi:10.1016/j.clineuro.2008.06.014

41. Gorgulu A, Albayrak BS, Gorgulu E, Tural O. Postoperative cerebral abscess formation caused by Toxocara canis in a meningioma cavity. J Neurooncol (2006) 77(3):325-6. doi:10.1007/s11060-005-9040-x

42. Kazek B, Jamroz E, Mandera M, Bierzyńska-Macyszyn G, Kluczewska E, Marszał E. The cerebral form of toxocarosis in a seven-year-old patient. Folia Neuropathol (2006) 44(1):72-6.

43. Moreira-Silva SF, Rodrigues MG, Pimenta JL, Gomes CP, Freire LH, Pereira FEL. Toxocariasis of the central nervous system: with report of two cases. Rev Soc Bras Med Trop (2004) 37(2):169-74. doi:10.1590/S003786822004000200011

44. Bächli H, Minet JC, Gratzl O. Cerebral toxocariasis: a possible cause of epileptic seizure in children. Childs Nerv Syst (2004) 20(7):468-72. doi:10.1007/ s00381-004-0963-x

45. Hoffmeister B, Glaeser S, Flick H, Pornschlegel S, Suttorp N, Bergmann F. Cerebral toxocariasis after consumption of raw duck liver. Am J Trop Med Hyg (2007) 76(3):600-2.

46. Vidal JE, Sztajnbok J, Seguro AC. Eosinophilic meningoencephalitis due to Toxocara canis: case report and review of the literature. Am J Trop Med Hyg (2003) 69(3):341-3.

47. Zachariah SB, Zachariah B, Varghese R. Neuroimaging studies of cerebral "visceral larva migrans" syndrome. J Neuroimaging (1994) 4(1):39-40. doi:10.1111/jon19944139

48. Rüttinger P, Hadidi H. MRI in cerebral toxocaral disease. J Neurol Neurosurg Psychiatry (1991) 54(4):361-2. doi:10.1136/jnnp.54.4.361

49. Helsen G, Vandecasteele SJ, Vanopdenbosch LJ. Toxocariasis presenting as encephalomyelitis. Case Rep Med (2011) 2011:503913. doi:10.1155/2011/ 503913

50. Moiyadi A, Mahadevan A, Anandh B, Shivashankar RS, Chickabasavaiah YT, Shankar SK. Visceral larva migrans presenting as multiple intracranial and intraspinal abscesses. Neuropathology (2007) 27(4):371-4. doi:10.1111/j. 1440-1789.2007.00775.x

51. Marx C, Lin J, Masruha MR, Rodrigues MG, da Rocha AJ, Vilanova LCP, et al. Toxocariasis of the CNS simulating acute disseminated encephalomyelitis. Neurology (2007) 69(8):806-7. doi:10.1212/01.wnl.0000267664.53595.75

52. Sick C, Hennerici MG. Expect the unexpected: a case of isolated eosinophilic meningitis in toxocariasis. Case Rep Neurol (2014) 6(3):259-63. doi:10.1159/ 000369060

53. Cusguen P, Alvarez A. Meningoencefalitis por neurotoxocarosis. Acta Neurol Colomb (2013) 29:109-11.

54. Tobin E, Zhang J, Maton B. Meningoencephalitis and visceral larva migrans in a woman with intense exposure to cats. Infect Dis Clin Pract (2011) 19:221-2. doi:10.1097/IPC.0b013e3181f69a3c 
55. Singer OC, Conrad F, Jahnke K, Hattingen E, Auer H, Steinmetz H. Severe meningoencephalomyelitis due to CNS-toxocarosis. JNeurol (2011) 258(4):696-8. doi:10.1007/s00415-010-5807-x

56. Salvador S, Ribeiro R, Winckler MI, Ohlweiler L, Riesgo R. Pediatric neurotoxocariasis with concomitant cerebral, cerebellar, and peripheral nervous system involvement: case report and review of the literature. J Pediatr (Rio J) (2010) 86(6):531-4. doi:10.1590/S0021-75572010000600015

57. Maiga Y, Wiertlewski S, Desal H, Marjolet M, Damier P. [Presentation of cerebral toxocariasis with mental confusion in an adult: case report and review of the literature]. Bull Soc Pathol Exot (2007) 100(2):101-4.

58. Mrissa R, Battikh R, Ben Abdelhafidh N, Jemli B, Azzouz O, Zaouali J, et al. [Toxocara canis encephalitis: case report]. Rev Med Interne (2005) 26(10):829-32. doi:10.1016/j.revmed.2005.04.025

59. Xinou E, Lefkopoulos A, Gelagoti M, Drevelegas A, Diakou A, Milonas I, et al. CT and MR imaging findings in cerebral toxocaral disease. AJNR Am J Neuroradiol (2003) 24(4):714-8.

60. Komiyama A, Hasegawa O, Nakamura S, Ohno S, Kondo K. Optic neuritis in cerebral toxocariasis. J Neurol Neurosurg Psychiatry (1995) 59(2):197-8. doi:10.1136/jnnp.59.2.197

61. Choi J-H, Cho J-W, Lee J-H, Lee SW, Kim H-J, Choi K-D. Obstructive hydrocephalus due to CNS toxocariasis. J Neurol Sci (2013) 329(1-2):59-61. doi:10.1016/j.jns.2013.03.009

62. Feske SK, Goldberg M, Dudzinski DM, Gonzalez RG, Kovach AE. Case records of the Massachusetts General Hospital. Case 29-2015. A 38-year-old pregnant woman with headache and visual symptoms. N Engl J Med (2015) 373(12):1154-64. doi:10.1056/NEJMcpc1404335

63. Kwon HH. Toxocariasis: a rare cause of multiple cerebral infarction. Infect Chemother (2015) 47(2):137-41. doi:10.3947/ic.2015.47.2.137

64. Fellrath J-M, Magnaval J-F. Toxocariasis after slug ingestion characterized by severe neurologic, ocular, and pulmonary involvement. Open Forum Infect Dis (2014) 1(2):ofu063. doi:10.1093/ofid/ofu063

65. Lompo L-D, Kamdem F-K, Revenco E, Allibert R, Medeiros E, Vuillier F, et al. [Toxocara canis cerebral vasculitis revealed by iterative strokes]. Rev Neurol (Paris) (2012) 168(6-7):533-7. doi:10.1016/j.neurol.2012.02.008
66. Helbok R, Brenneis C, Engelhardt K, Beer R, Lackner P, Brössner G, et al. A rare case of Toxocara canis cerebral vasculitis. Eur J Neurol (2007) 14(1):e49. doi:10.1111/j.1468-1331.2006.01564.x

67. Dousset V, Sibon I, Menegon P. [Case no 6. Cerebral vasculitis due to Toxocara canis (or catis) origin]. J Radiol (2003) 84(1):89-91.

68. Sommer C, Ringelstein EB, Biniek R, Glöckner WM. Adult Toxocara canis encephalitis. J Neurol Neurosurg Psychiatry (1994) 57(2):229-31. doi:10.1136/ jnnp.57.2.229

69. Kayes SG, Oaks JA. Development of the granulomatous response in murine toxocariasis. Initial events. Am J Pathol (1978) 93(2):277-94.

70. Elefant GR, Shimizu SH, Sanchez MCA, Jacob CMA, Ferreira AW. A serological follow-up of toxocariasis patients after chemotherapy based on the detection of IgG, IgA, and IgE antibodies by enzyme-linked immunosorbent assay. J Clin Lab Anal (2006) 20(4):164-72. doi:10.1002/jcla.20126

71. Flanagan EP. Autoimmune myelopathies. Handb Clin Neurol (2016) 133:327-51. doi:10.1016/B978-0-444-63432-0.00019-0

72. Del Brutto OH, Nash TE, White AC Jr, Rajshekhar V, Wilkins PP, Singh G, et al. Revised diagnostic criteria for neurocysticercosis. J Neurol Sci (2017) 372:202-10. doi:10.1016/j.jns.2016.11.045

Conflict of Interest Statement: The authors declare that the research was conducted in the absence of any commercial or financial relationships that could be construed as a potential conflict of interest.

The reviewer $\mathrm{ZN}$ and handling editor declared their shared affiliation.

Copyright (c) 2018 Sánchez, García and Nicoletti. This is an open-access article distributed under the terms of the Creative Commons Attribution License (CC BY). The use, distribution or reproduction in other forums is permitted, provided the original author(s) and the copyright owner are credited and that the original publication in this journal is cited, in accordance with accepted academic practice. No use, distribution or reproduction is permitted which does not comply with these terms. 